\begin{tabular}{|c|l|}
\hline Title & Unemployment Policies in an Economy with A dverse Selection \\
\hline Author(s) & Kudoh, Noritaka \\
\hline Citation & $\begin{array}{l}\text { Bulletin of Economic Research, 59(2), 179-196 } \\
\text { https://doi.org/10.1111/.0307-3378.2007.00253.x }\end{array}$ \\
\hline Issue Date & 2007-04.05 \\
\hline Doc URL & http://hdl.handle.net/2115/38126 \\
\hline Rights & The definitive version is available at www.blackwell-synergy.com \\
\hline Type & article (author version) \\
\hline File Information & BER59-2.pdf \\
\hline
\end{tabular}

Instructions for use 


\title{
Unemployment Policies in an Economy with Adverse Selection*
}

\author{
Noritaka Kudoh $^{\dagger}$ \\ Hokkaido University
}

November 2, 2006

\begin{abstract}
This paper studies the effects of unemployment policies in a simple static general equilibrium model with adverse selection in the labor market. Firms offer a contract that induces the selfselection of workers. In equilibrium, all unskilled workers are screened out and some skilled workers are rationed out. It is shown that the provision of unemployment insurance (UI) raises involuntary unemployment by encouraging adverse selection, while unemployment assistance (UA) — or subsidy to unemployment — reduces involuntary unemployment. A simple efficiency wage model is also presented to show that either of the two policies reduces employment by taxing effort and subsidizing shirking. The key is whether the social role of unemployment is a sorting device or a worker discipline device.

JEL classification: D82, J65, J68
\end{abstract}

Keywords: adverse selection, sorting, involuntary unemployment, unemployment insurance

${ }^{*}$ I would like to thank two anonymous referees for their invaluable comments. I would also like to thank Nobuaki Hori, Ryoichi Imai, Daisuke Oyama, Takashi Shimizu, and the seminar participants at Kyushu University for their comments and discussions. All remaining errors are mine.

${ }^{\dagger}$ Department of Economics, Kita 9 Nishi 7, Kita-ku, Sapporo 060-0809, JAPAN; Email: kudoh@econ.hokudai.ac.jp 


\section{Introduction}

Government intervention in the labor market, or unemployment policies, are common. Many theories of unemployment are developed and used to assess the likely effects of labor market policies. ${ }^{1}$ In the simplest search model, for example, the provision of unemployment insurance (UI) works as a subsidy to rejecting a job, and thereby increases voluntary unemployment. ${ }^{2}$ This paper studies government intervention in the labor market by focusing on equilibrium involuntary unemployment. The key findings of this study are as follows: (1) the eligibility of unemployment benefit has a profound implication for the effect of intervention and (2) the effects of government intervention crucially depend on the source of unemployment.

The benchmark model employed in this paper is a simple static general equilibrium with adverse selection in the labor market. Equilibrium involuntary unemployment arises because of asymmetric information regarding the types of workers. Employers in such an environment announce a term that induces the self-selection of workers. As in other models of adverse selection, quantity rationing is observed in equilibrium, and this is the source of involuntary unemployment.

Unemployment policies under such circumstances differ from those under full information in many respects. Most notably, it is possible to assess the impact of unemployment policies on involuntary unemployment through workers' incentives to misrepresent their types. Since incentive compatibility and participation constraints define the equilibrium outcome in models with asymmetric information, important insights are obtained by investigating the impact of each policy on these constraints.

The model used in this paper is closely related to Bencivenga and Smith (1997) and, in particular, Betts and Bhattacharya (1998). Bencivenga and Smith (1997) developed a growth model with adverse selection in the labor market to describe the dynamics of rural-urban migration. Betts and Bhattacharya (1998) introduced credit market frictions in the Bencivenga-Smith model to investigate the interaction between credit market and labor market frictions.

\footnotetext{
${ }^{1}$ Snower and de la Dehesa (1997) is a volume focusing on issues relating to government intervention in the labor market.

${ }^{2}$ See, for example, Pissarides (1983, 1985).
} 
The basic structure of the model is as follows. Final goods may be produced in either the primary or secondary sector. There are two types of workers: skilled and unskilled. The unskilled workers are assumed to have zero productivity in the primary sector. In order to screen out the unskilled workers, the primary sector offers a contract, which comprises the wage rate and the employment probability, that attracts only the skilled workers. As an unfortunate by-product of the contract, some skilled workers are rationed out: they are involuntarily unemployed.

The analysis of the model suggests that an increase in the UI benefit raises equilibrium involuntary unemployment and reduces total welfare. This is because an increase in the benefit makes participation in the primary sector more attractive to all workers, including those who are unskilled. Since the unskilled workers are not qualified for the "good job," in order to discourage them from applying, primary sector firms are forced to reduce the employment probability. In other words, in an economy where unemployment is a sorting device, the provision of UI worsens adverse selection.

Atkinson (1992) and Atkinson and Micklewright (1991) emphasized the distinction between UI and unemployment assistance (UA) or a "subsidy to unemployment." According to Atkinson (1992), in many theoretical models the UI benefit is treated simply as a "wage when not working." In such models, an increase in the benefit leads to an increase in unemployment simply because leisure becomes more attractive. In the spirit of Atkinson (1992) and Atkinson and Micklewright (1991), this paper draws a comparison between UI and UA. Under the UI system, benefit is provided only to those who have tried and failed to acquire employment in the primary sector. On the other hand, UA is modeled as a benefit provided to those simply without a job. The purpose of this exercise is to verify whether or not the eligibility of the benefit has different effects and why.

The analysis reveals that UA reduces involuntary unemployment and raises welfare. This is because the policy encourages the self-selection of workers. In other words, raising generosity in terms of eligibility for unemployment benefit reduces information frictions. Lucas (1978) observed that "At one extreme, severe penalties to declaring oneself unemployed could reduce unemployment rates to any desired level. Such a policy would result in serious real output losses." Lucas (1978) 
also suggested that an output-maximizing UI scheme involves a subsidy to unemployment. This view appears to be consistent with the results under UA. A significant point made in this paper is that if unemployment acts as a sorting device, then similar policies like UI and UA will have opposite effects.

With risk-neutral agents, the driving force of the results is UI or UA as a subsidy to unemployment. Thus, if income redistribution occurs only among the workers who apply for a primary sector job, then UI will have no effect on equilibrium. This is precisely because with risk-neutral agents, UI does not function as insurance. In order to investigate the effect of UI as insurance, the model with risk-averse agents is studied. Since risk-averse agents are better off with insurance, UI as insurance encourages all workers to apply for a primary sector job. As a result, the adverse selection problem worsens and involuntary unemployment increases. This result is in contrast with Acemoglu and Shimer (1999, 2000), who argued that UI encourages workers' risk-taking and thereby encourages the creation of high-productivity jobs.

Interestingly, the logic applied in the adverse selection model does not necessarily hold in other models that generate involuntary unemployment. In order to draw a comparison, this paper develops a static version of the efficiency wage model and introduces the UI and UA policies. A framework suitable for this purpose is Jullien and Picard (1998), in which equilibrium involuntary unemployment is obtained as a result of worker moral hazard. In order to prevent shirking, employers offer a contract that is consistent with incentive compatibility and participation constraints. Unlike the adverse selection model, UI and UA work in the same direction: both policies reduce employment by taxing effort and subsidizing shirking. Thus, the effects of unemployment policies depend on whether the social role of unemployment is a sorting device or a worker discipline device. 


\section{The Model}

\subsection{Environment}

Consider a simple static economy with adverse selection in the labor market. The economy consists of workers of unit measure. There are two types of agents, skilled and unskilled. A fixed fraction $\lambda \in(0,1)$ of the population is of type $L$ or unskilled workers, and the remainder, $1-\lambda$, is of type $H$ or skilled workers. All agents know the distribution of types in the population, while each worker type is private information.

There are two sectors: primary and secondary. Both the sectors produce the same final product. However, the primary sector is more productive than the secondary sector. In other words, there are "good jobs" and "bad jobs." The primary sector requires inputs of skilled workers. The marginal product of labor is $A>0$ and is constant. This paper follows Bencivenga and Smith (1997) and Betts and Bhattacharya (1998) and assumes that type $L$ workers have zero productivity in the primary sector.

The secondary sector does not require any specific skills. In addition, it is assumed that jobs are abundant and that there is no information friction in this sector. One interpretation of this sector is that workers acquire part-time jobs. According to this interpretation, it is reasonable to assume that jobs are abundant and that secondary sector income is taxable. Alternatively, one could follow Betts and Bhattachrya's (1998) interpretation to consider an informal sector where each agent produces at home. In fact, several authors, including Nosal et al. (1992), emphasize the importance of self-employment and household production.

The productivity of a worker of type $i(i=H, L)$ in the secondary sector is denoted by $\beta_{i}$. In this section I assume that the activity in the secondary sector is regarded as market activity and is taxable. Later, I will consider the case in which secondary sector income is untaxable. If a worker of type $i$ does not seek a job in the primary sector, then he or she acquires a job in the secondary sector with certainty and receives an after-tax income of $(1-\tau) \beta_{i}$.

Participation in the primary sector is costly. In particular, I follow Betts and Bhattacharya (1998) and assume that an individual of type $i$ incurs a disutility of $s_{i}$, which may be considered 
as the cost of education or job search.

Each agent decides whether or not to seek employment in the primary sector. Suppose that he or she seeks a job in the primary sector. With probability $q$, which is determined as part of equilibrium, he or she finds employment in that sector and earns the after-tax wage income $(1-\tau) w$. With probability $1-q$, he or she fails to secure a job in that sector. Since secondary sector jobs are abundant, those who have tried and failed to attain a job in the primary sector receive $b+(1-\tau) \beta_{i}$, where $b$ is the unemployment benefit. The benefit should not be too attractive, so $b<\beta_{L}$ is assumed. It is noteworthy that UI in this environment works as a subsidy to applying for a primary sector job and does not function as insurance because agents are risk neutral. Section 4 explores the case in which agents are risk averse.

For a worker of type $i$, the expected utility of seeking a job in the primary sector is

$$
-s_{i}+q(1-\tau) w+(1-q)\left(b+(1-\tau) \beta_{i}\right) .
$$

The type $i$ workers' indifference curves on the $w$ - $q$ space have the slope

$$
\frac{d w}{d q}=-\frac{(1-\tau)\left[w-\beta_{i}\right]-b}{(1-\tau) q}
$$

It must be the case where $(1-\tau)\left[w-\beta_{i}\right]-b>0$. This condition simply states that the after-tax wage rate in the primary sector must exceed the after-tax income in the secondary sector plus the unemployment benefit. For a given level of $w$, a type $L$ worker's indifference curve is steeper than that of a type $H$ worker for any $q$ if and only if $\beta_{H}>\beta_{L}$. This condition is sufficient to guarantee the single-crossing condition (Rothschild and Stiglitz, 1976), as shown in Figure 1. The intuition of the single-crossing condition in this context is that if the employment probability is reduced, then a type $L$ worker demands more wage than a type $H$ worker.

\subsection{Contract}

Consider the representative firm of the economy. The equilibrium concept employed is Rothschild and Stiglitz's (1976) competitive screening. See also Mas-Colell et al. (1995). Given a set of policy variables, the firm announces a pair of a wage rate $w$ and employment probability $q$ such that 
workers self-select. Since a type $L$ worker has zero productivity in the primary sector, the firm wishes to make an announcement that discourages all type $L$ workers from applying. Thus, any equilibrium contract must satisfy

$$
\begin{aligned}
-s_{H}+q(1-\tau) w+(1-q)\left(b+(1-\tau) \beta_{H}\right) & >(1-\tau) \beta_{H}, \\
-s_{L}+q(1-\tau) w+(1-q)\left(b+(1-\tau) \beta_{L}\right) & \leq(1-\tau) \beta_{L} .
\end{aligned}
$$

These conditions state that skilled workers participate in the primary sector, while unskilled workers do not.

One might argue that the employment probability is unverifiable. In this case, there arises a time inconsistency problem. Since firms are aware that all applicants are of type $H$ in equilibrium, the firms have an incentive to employ all the applicants, which destroys the separating equilibrium. In order to rule out such a scenario, I assume that each firm can commit to its employment probability. One such device involves issuing letters of acceptance and rejection. With this assumption, the government can verify that an individual is indeed involuntarily unemployed.

Although implicit, there are potential competitors, and hence, the firm must earn zero profit. As in Rothschild and Stiglitz (1976), any equilibrium contract must maximize the expected utility of type $H$ individuals subject to (1), (2), and the zero-profit condition.

Proposition 1 Assume $\beta_{H}>\beta_{L}>b, A>\beta_{H}+b, s_{L}>b$, and $s_{H}=0$. The unique equilibrium contract $(w, q)$ induces a separating equilibrium and satisfies

$$
\begin{aligned}
w & =A, \\
q & =\frac{s_{L}-b}{(1-\tau)\left[w-\beta_{L}\right]-b} .
\end{aligned}
$$

Proof. Consider Figure 1. The equilibrium contract must maximize the type $H$ worker's utility, subject to (2) and $w \leq A$. Rewrite (2) as

$$
w=\frac{b}{1-\tau}+\beta_{L}+\frac{s_{L}-b}{(1-\tau) q}
$$

which indicates the indifference curve at which type $L$ individuals are indifferent between accepting and rejecting the contract. The solution to (3) and (4) is the candidate equilibrium and is depicted 
by point $\mathrm{E}$ in Figure 1. What remains is to verify that the strict inequality expressed in (1) is satisfied at the candidate equilibrium. Rewrite $(1)$ as $q\left[(1-\tau)\left(w-\beta_{H}\right)-b\right]>s_{H}-b$. It is evident that a sufficient condition for this condition to hold is to let $s_{H}=0$.

Similar results in closely related environments are found in Bencivenga and Smith (1997) and Betts and Bhattacharya (1998). In this environment, $\beta_{H}>\beta_{L}$ must hold for the existence of involuntary unemployment. To examine this, suppose for now that $\beta_{L}>\beta_{H}$ holds. In this case, the indifference curves for the type $H$ workers are steeper than those for the type $L$ workers; as a result, point $\mathrm{F}$ in Figure 1 will be the equilibrium contract. In other words, firms can induce self-selection with $q=1$ and $w<A$-this is a case of specialization rather than sorting. Since such a case is uninteresting, I focus on the case with $\beta_{H}>\beta_{L}$, under which sorting occurs in equilibrium.

\subsection{Equilibrium}

The taxable income for a type $H$ and type $L$ worker are $q w+(1-q) \beta_{H}$ and $\beta_{L}$, respectively. The total taxable income is therefore $(1-\lambda) q w+(1-\lambda)(1-q) \beta_{H}+\lambda \beta_{L}$. Thus, the government's budget constraint is given by

$$
(1-\lambda)(1-q) b=\left[(1-\lambda) q w+(1-\lambda)(1-q) \beta_{H}+\lambda \beta_{L}\right] \tau
$$

Thus, a market equilibrium is defined as a set of $\{w, q, \tau\}$ that solves (3), (4), and (5). Solve (5) for $\tau$ to obtain

$$
\tau=\frac{(1-\lambda)(1-q) b}{(1-\lambda) q A+(1-\lambda)(1-q) \beta_{H}+\lambda \beta_{L}} \equiv T(q)
$$

which describes the manner in which the employment probability and the tax rate are related in equilibrium. It is easy to verify that (a) $T(q)$ is decreasing and (b) $T(q) \in(0,1)$ for any $q \in[0,1]$. An increase in $q$ implies a reduction in the number of individuals who receive the unemployment benefit. This implies a lower tax rate. To check (a), differentiate (6) with respect to $q$ to yield

$$
T^{\prime}(q)=\frac{-(1-\lambda) b\left[(1-\lambda) A+\lambda \beta_{L}\right]}{\left[(1-\lambda) q A+(1-\lambda)(1-q) \beta_{H}+\lambda \beta_{L}\right]^{2}}<0 .
$$


To prove (b), verify that $T(q)<1$ if and only if $(1-\lambda)(1-q) b<(1-\lambda) q A+(1-\lambda)(1-q) \beta_{H}+$ $\lambda \beta_{L}$, which reduces to $(1-\lambda) q A+(1-\lambda)(1-q)\left(\beta_{H}-b\right)+\lambda \beta_{L}>0$; this is true since $\beta_{H}>b$.

Substitute (6) into (4) to obtain

$$
q=\frac{s_{L}-b}{(1-T(q))\left[A-\beta_{L}\right]-b} \equiv \Omega(q) .
$$

It is then easy to verify that $\Omega^{\prime}(q)<0$ for all $q$. In addition,

$$
\Omega(0)=\frac{s_{L}-b}{\left(1-\frac{(1-\lambda) b}{(1-\lambda) \beta_{H}+\lambda \beta_{L}}\right)\left[A-\beta_{L}\right]-b} \text { and } \Omega(1)=\frac{s_{L}-b}{A-\beta_{L}-b}
$$

hold. Since $\Omega$ is monotonically decreasing in $q$, there exists a unique solution to $q=\Omega(q)$ if $\Omega(1) \in(0,1)$. This condition is satisfied if $s_{L}>b, A>\beta_{L}+b$, and $A-s_{L}>\beta_{L}$ are satisfied. Figure 2 depicts the function $\Omega(q)$ and the market equilibrium of this economy.

Proposition 2 (a) An increase in $b$ reduces q; (b) An increase in A reduces $q$.

Proof. (a) It is sufficient to verify that an increase in $b$ shifts the $\Omega$ locus downward.

$$
\frac{\partial \Omega(q)}{\partial b}=\frac{-\left[(1-T(q))\left[A-\beta_{L}\right]-b\right]-\left(s_{L}-b\right)\left[-\frac{\partial T(q)}{\partial b}\left[A-\beta_{L}\right]-1\right]}{\left[(1-T(q))\left[A-\beta_{L}\right]-b\right]^{2}}<0
$$

holds since $\partial T(q) / \partial b>0$. (b) Differentiate the denominator of $\Omega(q)$ with respect to $A$ to obtain

$$
1-T(q)-\frac{\partial T(q)}{\partial A}\left[A-\beta_{L}\right]>0
$$

Thus, an increase in $A$ shifts the $\Omega$ locus downward.

Proposition 2(a) states that the provision of UI raises equilibrium involuntary unemployment. At first glance, the result is very standard. Indeed, the literature on UI has repeatedly produced the proposition that UI raises unemployment. ${ }^{3}$ However, such a proposition is obtained in many models of unemployment because UI is modeled as a subsidy to rejecting a contract, which obviously increases the duration of voluntary unemployment. The importance of Proposition 2(a) is its suggestion that UI raises involuntary unemployment. An increase in UI raises the value of accepting a contract. Since unskilled workers find the primary sector more attractive, UI makes screening

\footnotetext{
${ }^{3}$ See Atkinson and Micklewright (1991) and the references therein.
} 
more difficult. In order to discourage all type $L$ individuals from applying, the firm must reduce the employment probability.

An increase in $A$ may be viewed as a skill-biased technical progress because the productivity in the secondary sector is left unchanged. Proposition 2(b) implies that such a technical progress raises unemployment by worsening information frictions; a skill-biased technical progress makes the primary sector more attractive. Comparative statics exercises with respect to other structural parameters in a related model are found in Betts and Bhattacharya (1998).

This paper defines the total sum of the welfare of all individuals as the total welfare, although, in principle, it is difficult to define an appropriate measure of social welfare because individuals are heterogeneous ex ante and ex post. According to the definition, total welfare is written as

$$
W \equiv(1-\lambda) q\left[-s_{H}+(1-\tau) w\right]+(1-\lambda)(1-q)\left[-s_{H}+b+(1-\tau) \beta_{H}\right]+\lambda(1-\tau) \beta_{L}
$$

The government's budget constraint (5) can be used to reduce the above expression to $W=$ $(1-\lambda)\left[-s_{H}+q w+(1-q) \beta_{H}\right]+\lambda \beta_{L}$. It must be noted that $s_{H}=0$ and $w=A$. Thus,

$$
W=(1-\lambda)\left[q A+(1-q) \beta_{H}\right]+\lambda \beta_{L},
$$

from which it is easy to verify that $\partial W / \partial q=(1-\lambda)\left(A-\beta_{H}\right)>0$. This implies that unemployment reduces the total welfare because it changes the composition of good jobs. With Proposition 2, (8) implies that an increase in the UI benefit reduces the total welfare. ${ }^{4}$

\subsection{Neutrality Results}

Before concluding this section, it is useful to discuss some alternative formulations. First, suppose that the secondary sector income is untaxable. Then, any contract must satisfy $-s_{H}+q(1-$

\footnotetext{
${ }^{4}$ This result implies that the UI system needs to be terminated. The political economy literature suggests that it may not be very easy to eliminate an institution even if it is inefficient. Saint-Paul (1998, 2000), for example, suggested that employed workers or "insiders" may support for policies that raise unemployment. Here, the benefit is provided only to type $H$ individuals in equilibrium. This suggests that the political economy consideration might provide a rationale for the UI system in this economy. Such a consideration, however, is beyond the scope of this paper.
} 
$\tau) w+(1-q)\left(b+\beta_{H}\right)>\beta_{H}$ and $-s_{L}+q(1-\tau) w+(1-q)\left(b+\beta_{L}\right) \leq \beta_{L}$. The government's budget constraint is given by $(1-\lambda)(1-q) b=(1-\lambda) q w \tau$. Thus, the equilibrium employment probability is $q=s_{L} /\left(A-\beta_{L}\right)$. In this case, UI has no effect on employment.

Suppose that lump-sum tax is available. Then, any contract must satisfy $-s_{H}+q(w-\tau)+$ $(1-q)\left(b+\beta_{H}\right)>\beta_{H}$ and $-s_{L}+q(w-\tau)+(1-q)\left(b+\beta_{L}\right) \leq \beta_{L}$. The government's budget constraint is $(1-\lambda)(1-q) b=(1-\lambda) q \tau$. Thus, the equilibrium employment probability is given by $q=s_{L} /\left(A-\beta_{L}\right)$. Once again, UI does not influence employment in equilibrium.

Neutrality results are obtained because (i) since agents are risk neutral, the provision of insurance itself has no role beyond its income redistributive nature, and (ii) income redistribution only occurs among type $H$ workers, all of whom participate in the primary sector. With risk-neutral agents, UI works only as a subsidy to involuntary unemployment and not as insurance. In the following sections, I consider the cases in which (1) the generosity of eligibility for unemployment benefits is relaxed and (2) individuals are risk averse.

\section{Unemployment Assistance}

In the preceding section, unemployment is defined as those who have tried and failed to acquire a primary sector job. This is based on the view that the activity in the secondary sector is formal market activity. In that scenario, UI acts as a subsidy to applying for a good job. With information asymmetry, this type of subsidy worsens the adverse selection problem.

Does the provision of unemployment benefit always raise unemployment and reduce the total welfare? The purpose of this section is to present a model with UA instead of UI. The notion of UA is introduced and distinguished from that of UI by Atkinson (1992) and Atkinson and Micklewright (1991). According to Atkinson (1992), UI is provided to those who are involuntarily unemployed. In the context of the model of this paper, UI is provided to those who have tried and failed to acquire a primary sector job. On the other hand, the UA benefit is provided to those without a job. An important point made by Atkinson (1992) is that in many existing models, the distinction between UI and UA is not clear. 
In order to modify the model to match the scenario of UA, this section employs an alternative definition of the secondary sector. Namely, the secondary sector is regarded as an "informal sector" where each individual produces at home. Accordingly, secondary sector income is untaxable. Since individuals in the secondary sector are defined as unemployed or non-employed, they all receive unemployment benefit. This benefit is financed by proportional tax on the primary sector income.

Any contract must satisfy $-s_{H}+q(1-\tau) w+(1-q)\left(b+\beta_{H}\right)>b+\beta_{H}$ and $-s_{L}+q(1-\tau) w+$ $(1-q)\left(b+\beta_{L}\right) \leq b+\beta_{L}$. Therefore, the unique equilibrium contract satisfies

$$
\begin{aligned}
w & =A, \\
q & =\frac{s_{L}}{(1-\tau) w-\beta_{L}-b} .
\end{aligned}
$$

In this economy, the total taxable income is only $(1-\lambda) q w$ because all informal activities are assumed to be non-taxable. Thus, the government's budget constraint is

$$
(1-\lambda)(1-q) b+\lambda b=(1-\lambda) q w \tau
$$

Thus, a market equilibrium is given by a set of $\{w, q, \tau\}$ that solves (9), (10), and (11). Solve (11) for $\tau$ and substitute it into (10) to obtain $q=\left[(1-\lambda) s_{L}+b\right] /\left[(1-\lambda)\left(A-\beta_{L}\right)\right]$. It is then easy to establish the following.

Proposition 3 An increase in $b$ raises $q$.

Proposition 3 sharply contrasts with Proposition 2. UI and UA have opposite effects on equilibrium involuntary unemployment. This is because the former encourages unskilled workers to apply for primary sector jobs while the latter discourages them from doing so. In other words, UI raises the value of accepting a contract while UA raises the value of rejecting it.

The total welfare is defined by

$$
W \equiv(1-\lambda) q\left[-s_{H}+(1-\tau) w\right]+(1-\lambda)(1-q)\left[-s_{H}+b+\beta_{H}\right]+\lambda\left[b+\beta_{L}\right]
$$

Use the government's budget constraint (11) to rewrite it as $W=(1-\lambda)\left[q A+(1-q) \beta_{H}\right]+\lambda \beta_{L}$, where $s_{H}=0$ is imposed and $w=A$ holds in equilibrium. It is then easy to establish that an increase in UA raises the total welfare by promoting employment. 
In the basic search model, the unemployment benefit should be viewed as UA because it increases the value of not taking a job available to an individual (Atkinson and Micklewright, 1991). An increase in the unemployment benefit raises unemployment because the unemployed become selective. Thus, UA raises voluntary unemployment. As suggested by Marimon and Zilibotti (1999), Acemoglu and Shimer (1999, 2000), and Acemoglu (2001), such an increase in unemployment may enhance productivity by influencing the composition of high-productivity jobs. With asymmetric information, UA increases the total output because it directly improves the composition of high-productivity jobs.

Before closing this section, consider the case in which lump-sum tax is available. Any contract must satisfy $-s_{H}+q(w-\tau)+(1-q)\left(b+\beta_{H}\right)>b+\beta_{H}$ and $-s_{L}+q(w-\tau)+(1-q)\left(b+\beta_{L}\right) \leq b+\beta_{L}$. The government's budget constraint is $[(1-\lambda)(1-q)+\lambda] b=(1-\lambda) q \tau$. Thus, the equilibrium employment probability is given by $q=[(1-\lambda)+b] /\left[(1-\lambda)\left(A-\beta_{L}\right)\right]$. Therefore, UA raises employment.

\section{Risk Aversion}

As is now clear, if there is no income redistribution across agents of different types with the riskneutral agents, UI is neutral. The purpose of this section is to introduce risk-averse individuals to assess the effect of UI as "insurance."

Suppose that utility from consumption is given by the standard von Neumann and Morgenstern utility $u($.$) with u^{\prime}>0>u^{\prime \prime}$. The self-selection conditions are $-s_{H}+q u((1-\tau) w)+(1-q) u\left(b+\beta_{H}\right)>$ $u\left(\beta_{H}\right)$ and $-s_{L}+q u((1-\tau) w)+(1-q) u\left(b+\beta_{L}\right) \leq u\left(\beta_{L}\right)$. Assuming $\beta_{H}>\beta_{L}>b, A>\beta_{H}+b$, $s_{L}>b$, and $s_{H}=0$, it is easy to establish that the unique equilibrium contract $(w, q)$ induces a separating equilibrium and satisfies

$$
\begin{aligned}
w & =A \\
q & =\frac{u\left(\beta_{L}\right)+s_{L}-u\left(b+\beta_{L}\right)}{u((1-\tau) w)-u\left(b+\beta_{L}\right)} .
\end{aligned}
$$


The government's budget constraint is

$$
(1-\lambda)(1-q) b=(1-\lambda) q w \tau
$$

For the tax rate to be less than one, $b<A q /(1-q)$ or $q>b /(A+b)$ must hold.

A market equilibrium is defined as a set of $\{w, q, \tau\}$ that solves (12), (13), and (14). Solve (14) for $\tau$ and substitute it into (13) to obtain

$$
q=\frac{u\left(\beta_{L}\right)+s_{L}-u\left(b+\beta_{L}\right)}{u(A+b-b / q)-u\left(b+\beta_{L}\right)} .
$$

The equilibrium is given by the solution to (15). It is easy to verify that the right-hand side of (15) is decreasing in $q$.

Proposition 4 An increase in $b$ reduces $q$.

Proof. Totally differentiate (15) and arrange the terms to obtain

$$
\frac{d q}{d b}=-\frac{(1-q)\left[u^{\prime}\left(b+\beta_{L}\right)-u^{\prime}(A+b-b / q)\right]}{u(A+b-b / q)-u\left(b+\beta_{L}\right)+u^{\prime}(A+b-b / q) b / q} .
$$

Since $A+b-b / q>b+\beta_{L}$, it is evident that $u(A+b-b / q)>u\left(b+\beta_{L}\right)$ and $u^{\prime}\left(b+\beta_{L}\right)>$ $u^{\prime}(A+b-b / q)$.

Thus, if agents are risk averse, an increase in the UI benefit raises equilibrium involuntary unemployment even if UI works only as insurance. When UI redistributes income among type $H$ in different states of employment, risk-neutral agents are indifferent between contracts with different levels of the UI benefit because the expected income is invariant. Thus, the provision of such a benefit does not influence the value of applying for a good job, and therefore, such a policy is neutral. On the other hand, if agents are risk averse, the provision of UI itself raises the value of applying for a good job because risk-averse individuals wish to smooth the consumption level across different states of employment.

Acemoglu and Shimer (1999, 2000) argued that UI encourages workers' risk-taking, which results in the creation of high-productivity jobs. As pointed out in footnote 7 in Acemoglu and Shimer (2000), the analysis in this section suggests that with vertical heterogeneity of workers and asymmetric information regarding worker types, the provision of UI as insurance encourages adverse selection; it attracts workers who are not qualified for a high-productivity job. 


\section{Moral Hazard and Unemployment Policies}

\subsection{Environment}

Another important branch of studying equilibrium unemployment is the efficiency wage model, the reference for which includes Shapiro and Stiglitz (1984), Atkinson (1992), and Jullien and Picard (1998). This model also generates equilibrium involuntary unemployment, but as a result of hidden action rather than hidden information. The purpose of this section is to present a simple efficiency wage model to compare the results with those of the adverse selection model.

There are many variants of the efficiency wage model of equilibrium unemployment. The model of Jullien and Picard (1998) is particularly useful here because it essentially involves a one-period economy, although it is integrated into the dynamic general equilibrium model..$^{5}$

Consider a static version of Jullien and Picard (1998). In this economy, worker types are public information but workers' efforts are private information. A worker may either exert full effort or shirk completely. Agents are risk neutral. If an individual is employed and exerts full effort, then his or her utility is $y-v-a$, where $y$ denotes the after-tax income, $v$ is the parameter that captures disutility of being employed (because of reduced leisure), and $a$ is the utility cost of effort. If an individual is employed and shirk completely, then his utility is $y-v$. If he or she is unemployed, then his utility equals $y$. The value of $v$ is the same for all workers. Following Jullien and Picard (1998), I assume that workers are heterogeneous and that each worker type is characterized by the value of $a$. Let $L(a)$ be the distribution function with support $[\underline{a}, \infty)$, where $\underline{a}>0$. The total number of workers is normalized to one, implying that $\lim _{a \rightarrow \infty} L(a)=1$. Thus, the rate of unemployment in this economy is defined as $1-L(a)$.

To make the model comparable to that of adverse selection, I assume that the aggregate production function is $A \bar{e} l$, where $A$ is the marginal product of labor, $\bar{e}$ is the fraction of workers exerting full effort, and $l$ denotes the number of workers. As in the model of adverse selection, firms wish to design a contract that ensures $\bar{e}=1$.

\footnotetext{
${ }^{5}$ See also Bhattacharya and Chakraborty (2005), who employed the Jullien-Picard model to explore the link between labor and credit markets in the neoclassical growth model.
} 
The crucial features of Jullien and Picard (1998) are: (i) each worker type $a$ is observable, and (ii) if a worker exerts full effort, then his or her signal reveals that with certainty, while if he or she shirks, then his or her signal reports high effort with probability $\theta \in(0,1)$. Since a shirker cannot contribute to production and failing to convey a good signal necessarily implies that he or she is a shirker, a firm will fire those who have failed to convey a good signal.

\subsection{Equilibrium with Unemployment Insurance}

Consider an employed worker of type $a$. He or she will exert full effort if and only if

$$
(1-\tau) w(a)-v-a \geq[\theta(1-\tau) w(a)+(1-\theta) \beta]-v
$$

The right-hand side of (16) reflects that a worker will be fired if he or she fails to convey a good signal. In such a case, he or she ultimately works in the informal sector and receives $\beta \geq 0$, which is the same for all individuals. Rewrite this incentive compatibility condition as

$$
(1-\theta)[(1-\tau) w(a)-\beta] \geq a .
$$

The participation constraint is

$$
(1-\tau) w(a)-v-a \geq \beta
$$

If the incentive compatibility condition (17) binds and the participation condition (18) does not bind, then there exists involuntary unemployment. Following Jullien and Picard (1998), I assume $v \leq \theta \underline{a} /(1-\theta)$, under which (17) implies that (18) is slack.

Applying the logic of Jullien and Picard (1998), it is evident that the equilibrium contract is a pair of $\{\hat{a}, w\}$ such that (i) all workers of $a \leq \hat{a}$ are employed and (ii) $w(a)=w$ holds for $a \leq \hat{a}$. Thus, $\hat{a}$ and $w$ satisfy (17) at equality. It is then easy to verify that $\partial \hat{a} / \partial b=0$ and $\partial \hat{a} / \partial \tau<0$. These features of the model are important. Unlike the adverse selection model, the presence of UI does not influence the incentive compatibility condition. However, the tax reduces the value of exerting full effort.

Under the equilibrium contract, the total number of workers employed is $L(\hat{a})$ while $1-L(\hat{a})$ will be the total number of unemployed workers. As in the preceding sections, I introduce UI and 
UA into this economy. The government's budget constraint is $L(\hat{a}) \tau w=(1-L(\hat{a})) b$.

Equilibrium with involuntary unemployment is defined by a set of $\{w, l, \tau\}$ such that

$$
\begin{aligned}
w & =A, \\
l & =L((1-\theta)[(1-\tau) w-\beta]), \\
l \tau w & =(1-l) b
\end{aligned}
$$

hold and (18) is satisfied with strict inequality. (19) defines the labor demand curve and (20) is the familiar non-shirking condition (NSC). The tax rate cannot be too high. First, from (21), $\tau<1$ holds if and only if $b<A l /(1-l)$ or equivalently $l>b /(A+b)$. In addition, it is necessary that the participation constraint is not violated: $(1-\tau) A-v-\beta>\underline{a}$, which defines the upper bound of the tax rate: $\tau<1-[\underline{a}+v+\beta] / A$.

Substitute (19) and (21) into (20) to obtain

$$
l=L((1-\theta)[A-\beta+b-b / l]) .
$$

Consider the case in which $A$ is sufficiently large and the $b$ is sufficiently small so that the tax rate is sufficiently small. Then, (22) yields the equilibrium. ${ }^{6}$ It is easy to establish that an increase in UI benefit reduces employment. In contrast to the adverse selection model, UI does not directly affect workers' incentives. UI reduces employment because it raises tax, which reduces the value of exerting full effort. In addition, a decrease in employment leads to an increase in the number of individuals who receive unemployment benefit, which reinforces the upward pressure on the tax rate.

\footnotetext{
${ }^{6}$ To be precise, two equilibria are possible in this economy, one is associated with a low tax rate and high employment, and the other with a high tax rate and low employment. The source of multiplicity is the government rather than moral hazard. In fact, under full information, the equilibrium is given by $l=L([(1-\tau) A-v-\beta])$ and $l \tau A=(1-l) b$, and multiplicity persists. Thus, the tax policy alone has caused multiple equilibria. See Chapter 7 of Cooper (1999) on this issue. In this paper, I focus on the equilibrium that is comparable to Jullien and Picard (1998) and ignore the other, inferior, equilibrium.
} 


\subsection{Equilibrium with Unemployment Assistance}

Consider an employed worker of type $a$. He or she will exert full effort if and only if

$$
(1-\tau) w(a)-v-a \geq[\theta(1-\tau) w(a)+(1-\theta)(b+\beta)]-v
$$

In this case, if a worker is fired, then he or she receives the unemployment benefit $b$ plus $\beta$. Rewrite this incentive compatibility condition as $(1-\theta)[(1-\tau) w(a)-b-\beta] \geq a$. The participation constraint is $(1-\tau) w(a)-v-a \geq b+\beta$. The benefit $b$ appears in these conditions because the UA benefit, by assumption, is provided to those without a job. It is easy to verify that $\partial \hat{a} / \partial b<0$ and $\partial \hat{a} / \partial \tau<0$. Under UA, the presence of the benefit influences the incentive compatibility condition negatively because UA is provided to individuals even when they are fired due to their misconducts. In this economy, the provision of UA acts as a subsidy to shirking.

The government's budget constraint is $L(\hat{a}) \tau w=(1-L(\hat{a})) b$, which is identical to that for UI. This is because in equilibrium, there is no shirking or non-participation. Thus, the presence of UA influences the equilibrium outcome only through the incentive compatibility condition.

Equilibrium with involuntary unemployment is defined by a set of $\{w, l, \tau\}$ such that $w=A$, $l=L((1-\theta)[(1-\tau) w-b-\beta])$, and $l \tau w=(1-l) b$. Thus, the equilibrium is given by $l=$ $L((1-\theta)[A-\beta-b / l])$. In this case, the effect of an increase in $b$ is stronger than that in the model with UI because a change in the UA benefit directly influences the incentive compatibility condition, while the effect of UI is indirect. In the adverse selection model, the provision of UA reduces information frictions by subsidizing non-participation in the primary sector. In the moral hazard model, UA worsens information frictions by subsidizing shirking.

\section{Concluding Remarks}

This paper has considered a simple model of adverse selection to study the effects of unemployment policies. Special attention has been paid to the manner in which each policy influences the contract that induces the self-selection of workers. The provision of UI raises involuntary unemployment by worsening information frictions while UA, which may be considered as a subsidy to unemployment, 
reduces unemployment. The apparently similar policies have opposite effects on unemployment because UI raises the value of accepting a contract while UA raises the value of rejecting it. In the moral hazard model, UI and UA are shown to raise unemployment because both policies raise the value of shirking. Thus, the effects of unemployment policies crucially depend on the source of unemployment as well as who receives and who pays for the unemployment benefits.

An important direction for future research involves a study of the effects of UI and UA in a dynamic model with search frictions and adverse selection, possibly along the line of the research suggested by Montgomery (1999). According to the standard search theory, UA raises the value of waiting and thereby raises voluntary unemployment. The analysis in this paper reveals that UA reduces involuntary unemployment by reducing information frictions. A model with two features are required to assess the overall effects of UI and UA on equilibrium unemployment. 


\section{References}

[1] Acemoglu, Daron. "Good Jobs versus Bad Jobs," Journal of Labor Economics 19 (2001) 1-21.

[2] Acemoglu, Daron, and Robert Shimer. "Efficient Unemployment Insurance," Journal of Political Economy 107 (1999) 893-928.

[3] Acemoglu, Daron, and Robert Shimer. "Productivity Gains from Unemployment Insurance," European Economic Review 44 (2000) 1195-1224.

[4] Atkinson, Anthony B. "Institutional Features of Unemployment Insurance and the Working of the Labor Market," in Dasgupta et al. editors., Economic Analysis of Markets and Games, Essays in Honor of Frank Hahn, MIT Press (1992).

[5] Atkinson, Anthony B, and John Micklewright. "Unemployment Compensation and Labor Market Transitions: A critical Review," Journal of Economic Literature (1991) 1679-1727.

[6] Bencivenga, Valerie R., and Bruce D. Smith. "Unemployment, Migration, and Growth," Journal of Political Economy 105 (1997) 582-608.

[7] Betts, Caroline, and Joydeep Bhattacharya. "Unemployment, Credit Rationing, and Capital Accumulation: A Tale of Two Frictions," Economic Theory 12 (1998) 489-517.

[8] Bhattacharya, Joydeep, and Shankha Chakraborty. "What Do Information Frictions Do?" Economic Theory 26 (2005) 651-675.

[9] Cooper, Russell W. Coordination Games, Cambridge University Press, 1999.

[10] Jullien, Bruno, and Pierre Picard. "A Classical Model of Involuntary Unemployment: Efficiency Wages and Macroeconomic Policy," Journal of Economic Theory 78 (1998) 263-285.

[11] Lucas, Robert. "Unemployment Policy" American Economic Review (1978) 353-357.

[12] Marimon, Ramon and Fabrizio Zilibotti. "Unemployment vs. Mismatch of Talents: Reconsidering Unemployment Benefits," Economic Journal 109 (1999) 266-291. 
[13] Mas-Colell, Andrew, Michael D. Whinston, and Jerry R. Green. Microeconomic Theory, Oxford University Press, New York, 1995.

[14] Montgomery, James D. "Adverse Selection and Employment Cycles," Journal of Labor Economics 17 (1999) 281-297.

[15] Nosal, Ed, Richard Rogerson, and Randall Wright. "The Role of Household Production in Models of Involuntary Unemployment and Underemployment." Canadian Journal of Economics 25 (1992) 507-520.

[16] Pissarides, Christopher A. "Efficiency Aspects of the Financing of Unemployment Insurance and Other Government Expenditure," Review of Economic Studies 50 (1983) 57-69.

[17] Pissarides, Christopher A. "Taxes, Subsidies and Equilibrium Unemployment," Review of Economic Studies 52 (1985) 121-133.

[18] Rothschild, Michael, and Joseph Stiglitz. "Equilibrium in Competitive Insurance Markets: An Essay on the Economics of Imperfect Information," Quarterly Journal of Economics 91 (1976) 629-649.

[19] Saint-Paul, Gilles. "A Framework for Analyzing the Political Support for Active Labor Market Policy," Journal of Public Economics 67 (1998) 151-165.

[20] Saint-Paul, Gilles. The Political Economy of Labour Market Institutions, Oxford University Press, 2000.

[21] Shapiro, Carl and Joseph Stiglitz. "Equilibrium Unemployment as a Worker Discipline Device," American Economic Review 74 (1984) 433-444.

[22] Snower, Dennis J. and Guillermo de la Dehesa (editors). Unemployment Policy, Cambridge University Press, 1997. 
Figure 1: Equilibrium Contract

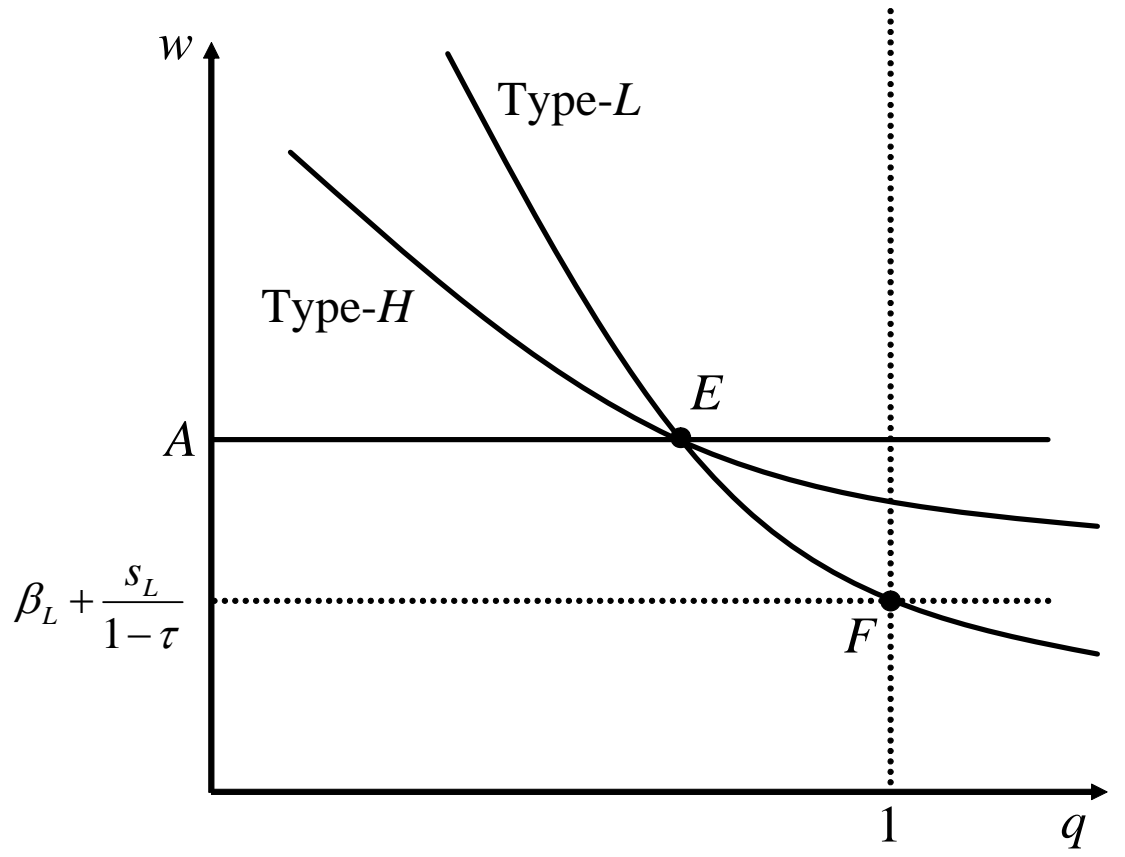

Figure 2: Market Equilibrium

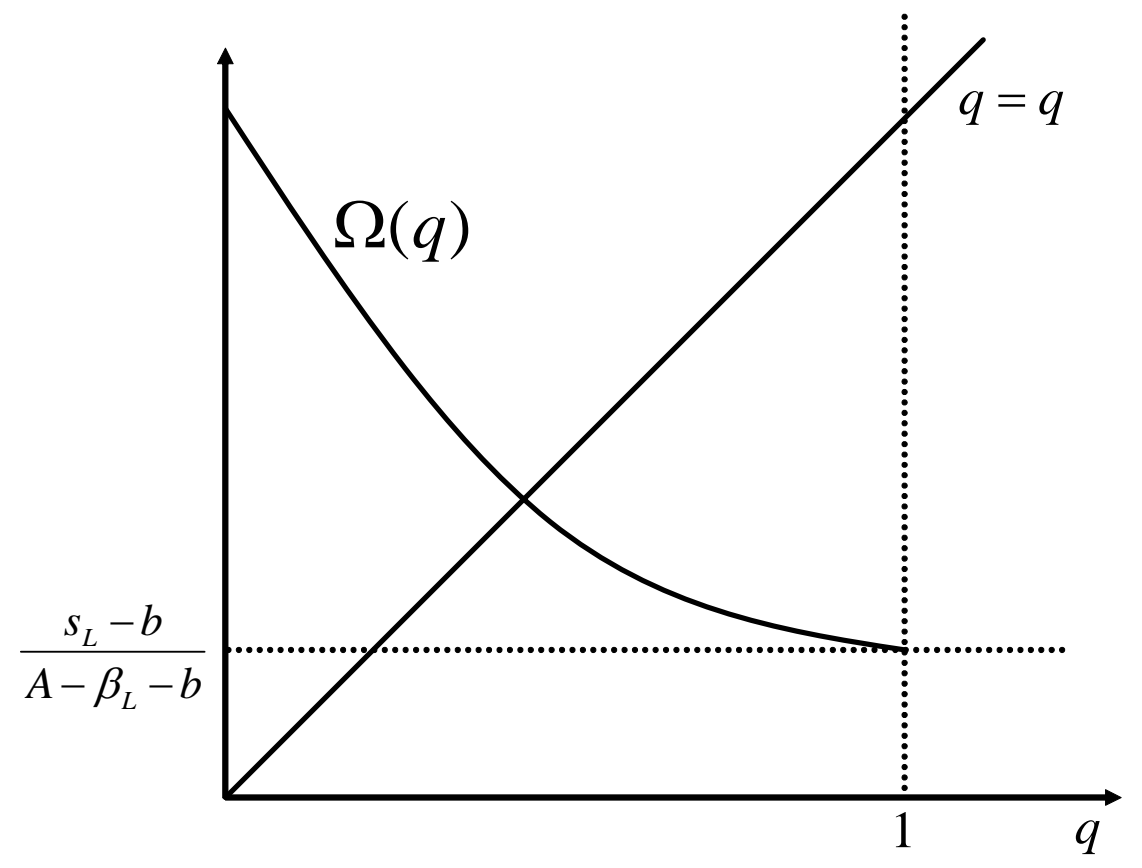

